\title{
A Comparative Evaluation of Total Laparoscopic Hysterectomy and Laparoscopic Supracervical Hysterectomy for Benign Uterine Diseases
}

\author{
Kavita Khoiwal@ ${ }^{1}$, Pradeep Garg ${ }^{2}$, Alka Kriplani ${ }^{3}$
}

\begin{abstract}
Background: Laparoscopic supracervical hysterectomy (LSH) is a minimally invasive alternative to total laparoscopic hysterectomy (TLH), which is a common procedure in developed countries. The study aimed to evaluate the safety (risks vs benefits) of LSH in the Indian scenario when compared with TLH in terms of intraoperative and postoperative outcome measures. Furthermore, quality of life (bladder, bowel, and sexual functions) was also evaluated.

Materials and methods: A prospective randomized study among 30 patients with benign uterine pathology for hysterectomy was included in the study. Patients were divided randomly into LSH $(n=15)$ and TLH $(n=15)$ groups. Intraoperative outcome measures, such as operation time, blood loss, and visceral injuries were noted. Postoperative outcome measures included absolute change in hemoglobin (Hb), duration of hospital stay, pain, urinary complaints (retention, dysuria), and bladder, bowel and sexual functions for 6 months.

Results: Demographic data were comparable in both groups. The operating time and blood loss were more in LSH than TLH group, ( $p=0.29$ and 0.37). The absolute change in hemoglobin was more in LSH group than TLH group $(p=0.001)$. Postoperative pain was indifferent in both the groups on postoperative day 0 and day 7 but it was significantly less in LSH group on day $1(p=0.03)$. Duration of hospital stay was similar in both groups. No patient required readmission. Patients in TLH group took a lesser number of days to return to routine activity compared to LSH group. The postoperative bladder, bowel, and sexual functions were comparable. The incidence of post-LSH vaginal bleeding was $13.3 \%$. No vault prolapse was noted at the end of 6 months follow-up.

Conclusion: Laparoscopic supracervical hysterectomy is safe and efficacious as TLH for benign uterine pathologies but has no extra benefits rather is associated with a persistent risk of developing cervical diseases and malignancy.

Keywords: Abnormal uterine bleeding, Fibroid uterus, Laparoscopic supracervical hysterectomy, Total laparoscopic hysterectomy.

World Journal of Laparoscopic Surgery (2021): 10.5005/jp-journals-10033-1442
\end{abstract}

\section{BACKGROUND}

Hysterectomy is a common gynecological surgery. The prevalence of hysterectomy in India ranges from 1.7 to $7.8 \%$. ${ }^{1}$ Vaginal route is always preferred as it obviates the need for abdominal incision but in cases where the vaginal route is not feasible laparoscopic hysterectomy is better than abdominal hysterectomy. ${ }^{2}$ Laparoscopic hysterectomy is now being performed globally, primarily because of lower morbidity and faster recovery time.

The laparoscopic supracervical hysterectomy (LSH) provides yet another minimally invasive approach in which the body of the uterus is removed while the cervix is preserved. LSH is less invasive compared to other approaches of hysterectomy and has also been referred to as pain-less hysterectomy. The LSH procedure does not require the woman to lose her cervix which seems to be a major concern for many women who need to have a hysterectomy. With the development of screening techniques and minimally invasive methods to treat cervical intraepithelial lesions, the removal of the cervix at the time of hysterectomy in low-risk patients is more of a preference than a requirement. The advantages of LSH include minimal invasion, improved sexual function, fewer urinary complications, and preservation of the cervix with its ligamentous supports. Simultaneously, LSH is associated with persistent risk of cervical disease, persistent vaginal bleeding, pelvic pain, and complications with future surgery if required. Therefore, LSH should

\footnotetext{
1Department of Obstetrics and Gynaecology, All India Institute of Medical Sciences, Rishikesh, Uttarakhand, India

2,3 Department of Obstetrics and Gynaecology, All India Institute of Medical Sciences, New Delhi, India

Corresponding Author: Kavita Khoiwal, Department of Obstetrics and Gynaecology, All India Institute of Medical Sciences, Rishikesh, Uttarakhand, India, Phone: +91 9690396908, e-mail: kavita.kh27@gmail.com

How to cite this article: Khoiwal K, Garg P, Kriplani A. A Comparative Evaluation of Total Laparoscopic Hysterectomy and Laparoscopic Supracervical Hysterectomy for Benign Uterine Diseases. World J Lap Surg 2021;14(1):30-33.

Source of support: Nil

Conflict of interest: None

Ethical approval: The study has been approved by institutional ethical board. Research involved human participants. Informed consent was taken from all the participants.
}

be recommended for benign uterine pathologies with no history of cervical dysplasia. ${ }^{3}$

Cooper et al. ${ }^{4}$ found LSH more effective than endometrial ablation without increasing the risk of complications and proposed LSH as a potential mode of hysterectomy. Other studies suggested

(0) Jaypee Brothers Medical Publishers. 2021 Open Access This article is distributed under the terms of the Creative Commons Attribution 4.0 International License (https://creativecommons.org/licenses/by-nc/4.0/), which permits unrestricted use, distribution, and non-commercial reproduction in any medium, provided you give appropriate credit to the original author(s) and the source, provide a link to the Creative Commons license, and indicate if changes were made. The Creative Commons Public Domain Dedication waiver (http://creativecommons.org/publicdomain/zero/1.0/) applies to the data made available in this article, unless otherwise stated. 
that LSH is associated with a more rapid postoperative recovery in terms of resumption of normal activity than a total laparoscopic hysterectomy (TLH). ${ }^{5,6}$ LSH is also been considered as the best surgical approach for abnormal uterine bleeding (AUB) by some authors as the overall patient satisfaction was quite high. ${ }^{7}$

Most of the literature regarding LSH is coming from developed countries. In India, TLH is a common surgery but we could not find any data on LSH, might be because it is not popular in developing countries due to high risk of cervical neoplasia, non-availability of regular cervical cancer screening and unawareness when available.

Therefore, we conducted this study to evaluate the safety (risks vs benefits) of LSH in the Indian scenario when compared with TLH in terms of intraoperative and postoperative outcome measures. Furthermore, quality of life (bladder, bowel, and sexual functions) was also evaluated.

\section{Materials and Methods}

It was a prospective randomized study conducted in the Department of Obstetrics and Gynaecology, All India Institute of Medical Sciences, New Delhi for 2 years. The study was reviewed and approved by the Institutional ethical board. All the patients presented to gynaecology OPD were invited to participate in the study. A total of 30 patients having a benign disease of the uterus with a surgical indication for hysterectomy who were willing to comply with the protocol and regular follow-up were included in the study. Patients with premalignant and malignant disease of uterus, cervix or ovaries/adnexa, complex adnexal mass, pregnancy, genital prolapse, coagulation disorders, and patients unfit for anesthesia were excluded from the study. Informed and written consent was obtained from all the patients. Women undergoing LSH were also counseled about the need for pap smear screening.

Patients were divided randomly into LSH $(n=15)$ and TLH $(n=15)$ groups by a computer-generated randomization list. All patients underwent detailed preoperative evaluation including a complete history, physical and pelvic examination, Papanicolaou (PAP) smear, endometrial aspiration (EA), transvaginal ultrasonography (using 6.5 MHz vaginal transducers, ultrasound machine- GEC LOGIQ 3 $\mathrm{PRO})$, and routine laboratory tests. All surgeries were done by the same surgeon.

Apart from routine steps of TLH, the body of the uterus was amputated from the cervix after bilateral uterine arteries coagulation and the endocervical canal was cauterized with bipolar cautery in LSH. The uterus was then morcellated using an electronic uterine morcellater.

Intraoperative outcome measures, such as operation time, blood loss, visceral injuries (bladder, bowel, ureter), need for blood transfusion (BT), conversion to laparotomy, and weight of uterus were noted.

Postoperative outcome measures included absolute change in hemoglobin $(\mathrm{Hb})$, fever, pain, BT, duration of hospital stay, urinary complaints (retention, dysuria), wound infection, duration and the number of doses of analgesic drugs given, and readmission. Operation time was calculated from the skin incision to skin closure. Postoperative pain was evaluated from the visual analog scale (VAS), ranges from 0 to 10 as no pain to worst pain possible. As a routine, injectable analgesic was discontinued on a postoperative day one in all patients and further doses were given only on demand. Oral analgesic was given in the form of a fixed dose combination of ibuprofen $400 \mathrm{mg}$ and paracetamol $500 \mathrm{mg}$. The number of analgesic tablets and vials requested by the patients was also recorded. Hemoglobin was sent in all patients 24 hours after surgery. The absolute change in hemoglobin was obtained by subtracting the mean 24 hours postoperative hemoglobin from the mean preoperative hemoglobin. Follow-up was done at periodic intervals ( 1 week, 1 month, 2 months, 3 months, and 6 months after the surgery) and complaints, condition of wound, recuperation from surgery, bladder, bowel, and sexual function were noted on each follow-up visit.

Statistical analysis was done on software SPSS (SPSS Inc., Chicago, IL) using the Fisher's test, Student's t-test, and MannWhitney test. A value of $p<0.05$ was accepted as significant.

\section{Results}

A total of 55 patients were assessed for eligibility, out of which 30 patients were included in the study based on eligibility criteria. Fifteen patients underwent $\mathrm{LSH}$ and another 15 patients underwent $\mathrm{TLH}$ after randomization. Flowchart 1 shows the flow diagram of the study.

Flowchart 1: Flow diagram of the study

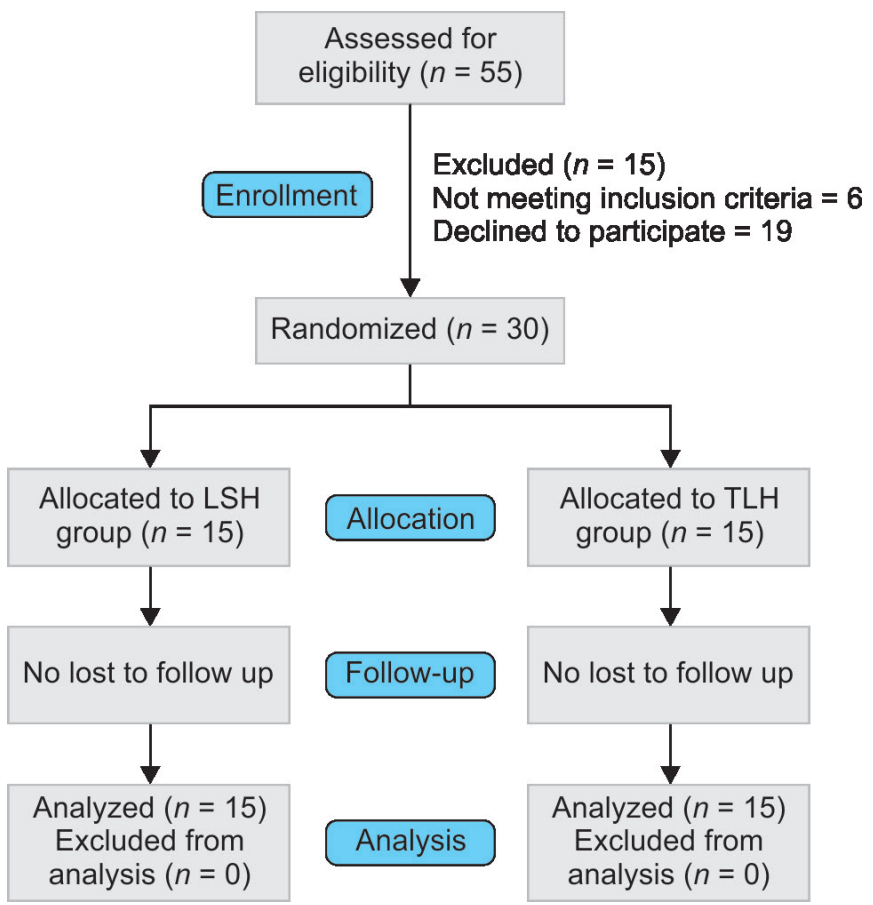

Demographic characteristics were similar in both the groups (Table 1). Most common indication was fibroid uterus. Incidentally, five patients in LSH group had previous cesarean $(p=0.042)$ while the groups were divided by randomization, which might be because of the small sample size.

Table 2 demonstrates perioperative outcomes. Operative time and blood loss were higher in LSH group though, the difference was not significant. The absolute fall in $\mathrm{Hb}$ was significantly more in LSH group $(p=0.001)$. We did not find any significant difference in VAS score on day 0 and day 7 but VAS score on day 1 and mean duration of injectable analgesics was significantly less in LSH group.

Recuperation from the surgery was similar in both the groups except the number of days to return to routine activity was significantly less in patients who underwent TLH compared to LSH group ( $p=0.02$ ). Patients in both groups reported no significant change in their bladder, bowel, and sexual function. Resumption of sexual activity was earlier in the LSH group though, the difference was not statistically significant (Table 3 ). 
Table 1: Demographic Characteristics

\begin{tabular}{llll}
\hline Variable & $L S H(n=15)$ & $T L H(n=15)$ & $p$-value \\
\hline Age (year) & $40.3 \pm 4.8$ & $44.3 \pm 8.1$ & 0.1 \\
BMI $\left(\mathrm{kg} / \mathrm{m}^{2}\right)$ & $23.3 \pm 3.4$ & $23.5 \pm 2.8$ & 0.8 \\
$\begin{array}{l}\text { Diagnosis (\%) } \\
\text { Fibroid }\end{array}$ & $9(60)$ & $10(66.6)$ & \\
AUB & $4(26.6)$ & $2(13.3)$ & \\
Adenomyosis & $2(13.3)$ & $1(6.6)$ & 0.8 \\
$\begin{array}{l}\text { Postmenopausal bleeding } \\
\text { Submucous polyp }\end{array}$ & 0 & $1(6.6)$ & \\
$\begin{array}{l}\text { Previous caesarean section } \\
\text { (\%) }\end{array}$ & $5(33.3)$ & 0 & 0.042 \\
$\begin{array}{l}\text { Previous major abdominal } \\
\text { surgery (\%) }\end{array}$ & $3(20)$ & $3(20)$ & 1 \\
\hline
\end{tabular}

Data presented as $n$ and mean $\pm \mathrm{SD} ; \mathrm{AUB}$, abnormal uterine bleeding; $\mathrm{BMI}$, body mass index

Table 2: Perioperative outcome measures in both the groups

\begin{tabular}{llll}
\hline Variable & $L S H(n=15)$ & $T L H(n=15)$ & $p$-value \\
\hline Operative time (mins) & $88.6 \pm 22.1$ & $86 \pm 27.2$ & 0.29 \\
Blood loss (mL) & $256 \pm 141.6$ & $210 \pm 107.5$ & 0.37 \\
$\begin{array}{l}\text { Uterine weight (g) } \\
\text { Absolute change }\end{array}$ & $254.4 \pm 221.7$ & $254.9 \pm 265.2$ & 0.7 \\
in Hb (g/dL) & $1.73 \pm 1.0$ & $1.23 \pm 0.5$ & 0.001 \\
$\begin{array}{l}\text { Intraoperative } \\
\text { complications }\end{array}$ & $0 / 15$ & $0 / 15$ & - \\
$\begin{array}{l}\text { Blood transfusion } \\
\text { Hospital stay (days) }\end{array}$ & $3 / 15$ & $1 / 15$ & \\
$\begin{array}{l}\text { Postoperative } \\
\text { complications }\end{array}$ & $0 / 15$ & $3.1 \pm 2.3$ & 0.49 \\
$\begin{array}{l}\text { Readmission } \\
\text { VAS day 0 }\end{array}$ & $0 / 15$ & $1 / 15$ & 1 \\
$\begin{array}{l}\text { VAS day 1 } \\
\text { VAS day 7 }\end{array}$ & $7.8 \pm 0.8$ & $8.2 \pm 0.6$ & 0.16 \\
$\begin{array}{l}\text { Injectable analgesics } \\
\text { (no. of days) }\end{array}$ & $1.8 \pm 0.4$ & $2.0 \pm 0.2$ & 0.04 \\
\hline Data prestedasnand & & $4.4 \pm 1.6$ & 0.03 \\
\hline
\end{tabular}

Data presented as $n$ and mean $\pm S D ; H b$, hemoglobin;VAS, visual analog scale

Two (13.3\%) out of fifteen patients in LSH group developed postoperative spotting per vaginum, managed by low dose oral contraceptive pills for 3 months.

On six month follow-up period, no patient was found to have vault prolapse.

\section{Discussion}

Hysterectomy by minimally invasive approach is now preferred as it obviates the need for a huge abdominal incision, longer hospital stay, longer convalescence time, and associated complications with added advantages of better visualization, faster recovery, less pain, and cosmetically better. We compared two types of laparoscopic hysterectomy.

One of the basic ideas behind performing supracervical hysterectomy was the total hysterectomy might lead to damage pelvic nerves or pelvic supports, which could increase the risk of urinary incontinence, bowel dysfunction, and reduces sexual pleasure. But in the present study, we did not find any significant
Table 3: Recuperation from surgery

\begin{tabular}{llll}
\hline Variable & $L S H(n=15)$ & $T L H(n=15)$ & $p$-value \\
\hline $\begin{array}{l}\text { Ability to take care of self } \\
\text { (days) }\end{array}$ & $7.2 \pm 1.2$ & $6.4 \pm 1.68$ & 0.14 \\
Routine activity (days) & $15.87 \pm 3.13$ & $13.47 \pm 2.30$ & 0.02 \\
Outdoor activity (days) & $27.07 \pm 4.6$ & $26.07 \pm 3.47$ & 0.50 \\
Urinary dysfunction & $0 / 15$ & $3 / 15$ & 0.22 \\
$\begin{array}{l}\text { Bowel dysfunction } \\
\text { Resumption of sexual }\end{array}$ & $0 / 15$ & $0 / 15$ & - \\
\begin{tabular}{l} 
activity (days) \\
\hline
\end{tabular} & 60.67 & 65.60 & 0.06 \\
\hline
\end{tabular}

Data presented as $n$ and mean \pm SD

difference in the postoperative bladder, bowel, and sexual functions in both groups. Cochrane review also suggested that supracervical hysterectomy does not improve outcomes for sexual, urinary, or bowel function as compared to total hysterectomy. ${ }^{8}$

Cipullo et al. ${ }^{9}$ did a retrospective cohort study for 7 years and reported shorter surgery time in the LSH group (100 min) than TLH group (110 min). Other studies also reported that the operating time and blood loss were less in LSH group when compared to TLH group. ${ }^{10-12}$ In the present study, we found that LSH was associated with slightly longer operation time and more blood loss compared to $T L H$, statistically insignificant. It could be the effect of a learning curve and extra time required for morcellation in LSH group.

Cipullo et al. ${ }^{9}$ reported a higher incidence of major complication rates (bladder, bowel, and ureteric injuries) in TLH group than LSH group (4.5 vs $1.3 \%$ ). Minor complications, such as wound infection, urinary tract infection, vaginal cuff abscess, and hematoma were comparable in both the groups (TLH: $13.3 \%$ and LSH: 13.4\%). Einarsson et al. ${ }^{10}$ and Boosz et al. ${ }^{11}$ also reported higher chances of intraoperative (visceral injuries), and postoperative complications in patients undergoing TLH. No intraoperative complications were noted in our study and only one patient in TLH group had a wound infection.

Postoperative pain and analgesic requirement were comparable in both the groups in previous studies. ${ }^{10,13}$ While, we found significantly less pain on day 1 of surgery and less need for injectable analgesics in LSH group than TLH group.

Ozgur et al. ${ }^{14}$ reported a $5.1 \%$ readmission rate in TLH group and $2.8 \%$ in LSH group. While no patient required readmission in our study.

Kafy et al. ${ }^{15}$ described improvement in overall health, body and self-images, and sexual function in both LSH and TLH groups. Some studies reported mean time to return to normal activity is earlier after LSH (2 weeks) than TLH (3 weeks).,

Einarsson et al. ${ }^{16}$ documented significantly better improvement in the short-term postoperative quality of life in terms of physical functioning, role physical, bodily pain, vitality, social functioning, and physical component summary in LSH group than TLH group. However, they did not find any difference in return to daily activities, perioperative pain, or use of pain medication. On the contrary, patients in our study took significantly longer time to return to normal activity with LSH group than TLH group and resumption of sexual activity was earlier in LSH group.

Berlit et al. ${ }^{17}$ published in their article that preservation of the cervix does not have any impact in improving sexual functioning postoperatively. Both LSH and TLH have a similar improvement in long-term sexual functioning in women who had impaired sexuality preoperatively. 
The incidence of postoperative vaginal bleeding was $13.3 \%$ in the LSH group in our study which is as per previous studies. Ghomi et al. ${ }^{18}$ and Lieng et al. ${ }^{3}$ reported the overall incidence of post-LSH vaginal bleeding as 19 and $0-25 \%$, respectively.

Hellstrom et al. ${ }^{19}$ described that the risk of development of carcinoma in the cervical stump is similar to the general population. In India, the incidence of carcinoma cervix is quite high and this was the probable reason behind the small sample size in our study. Routine cytological screening must be continued following a supracervical hysterectomy because of the persistent risk.

Prospective nature and randomization were strengths of the study. However, larger sample size and longer follow-up period would have produced more robust results and these are some limitations of the present study.

To the best of our knowledge, this is the first study from India comparing LSH with TLH. We postulate based on current data that supracervical hysterectomy has no added advantages over a total hysterectomy in terms of intraoperative and postoperative outcome measures as well as bladder, bowel, and sexual functions and in a country like India, where background incidence of carcinoma cervix is high, the decision should be individualized.

\section{Conclusion}

Laparoscopic supracervical hysterectomy is safe and efficacious as TLH for benign uterine pathologies but has no extra benefits rather associated with a persistent risk of developing cervical diseases and malignancy.

\section{OrCID}

Kavita Khoiwal: (1) https://orcid.org/0000-0002-3516-7486

\section{References}

1. Desai S, Shuka A, Nambiar D, et al. Patterns of hysterectomy in India: a national and state-level analysis of the Fourth National Family Health Survey (2015-2016). BJOG 2019;126(S4):72-80. DOI: 10.1111/14710528.15858.

2. Nieboer TE, Johnson $N$, Lethaby A, et al. Surgical approach to hysterectomy for benign gynaecological disease. Cochrane Database Syst Rev 2009;3:CD003677. DOI: 10.1002/14651858. CD003677.pub4.

3. Lieng $M$, Qvigstad $E$, Istre $O$, et al. Long-term outcomes following laparoscopic supracervical hysterectomy. BJOG 2008;115(13):16051610. DOI: 10.1111/j.1471-0528.2008.01854.x.

4. Cooper K, Breeman S, Scott NW, et al. Laparoscopic supracervical hysterectomy versus endometrial ablation for women with heavy menstrual bleeding (HEALTH): a parallel-group, open-label, randomised controlled trial. Lancet 2019;394(10207):1425-1436. DOI: 10.1016/S0140-6736(19)31790-8.

5. Johnson N, Barlow D, Lethaby A, et al. Surgical approach to hysterectomy for benign gynaecological disease. Cochrane Database Syst Rev 2006;3:CD003677. DOI: 10.1002/14651858.CD003677.pub4.

6. Jenkins TR. Laparoscopic supracervical hysterectomy. Am J Obstet Gynecol 2004;191(6):1875-1884. DOI: 10.1016/j.ajog.2004.06.096.

7. Zupi E, Zullo F, Marconi D, et al. Hysteroscopic endometrial resection versus laparoscopic supracervical hysterectomy for menorrhagia: a prospective randomized trial. Am J Obstet Gynecol 2003;188(1):7-12. DOI: 10.1067/mob.2003.60.

8. Lethaby A, Mukhopadhyay A, Naik R. Total versus subtotal hysterectomy for benign gynaecological conditions. Cochrane Database Syst Rev 2012;4:CD004993. DOI: 10.1002/14651858. CD004993.pub3.

9. Cipullo L, Paoli SD, Fasolino L, et al. Laparoscopic supracervical hysterectomy compared to total hysterectomy. JSLS 2009;13(3):370-375.

10. Einarsson J, Suzuki Y, Vellinga TT. Intramyometrial injection of vasopressin in laparoscopic supracervical hysterectomy. J Minim Invasive Gynecol 2008;15(2):197-201. DOI: 10.1016/j.jmig.2007.12.002.

11. Boosz A, Lermann J, Mehlhorn G, et al. Comparison of re-operation rates and complication rates after total laparoscopic hysterectomy (TLH) and laparoscopy-assisted supracervical hysterectomy (LASH). Eur J Obstet Gynecol Reprod Biol 2011;158(2):269-273. DOI: 10.1016/j. ejogrb.2011.04.021.

12. El-Mowafi D, Madkour W, Lall C, et al. Laparoscopic supracervical hysterectomy versus laparoscopic-assisted vaginal hysterectomy. J Am Assoc Gynecol Laparosc 2004;11(2):175-180. DOI: 10.1016/s10743804(05)60194-6.

13. Mueller A, Renner SP, Haeberle L, et al. Comparison of total laparoscopic hysterectomy and laparoscopy-assisted supracervical hysterectomy in women with uterine leiomyoma. Eur J Obstet Gyneco Reprod Biol 2009;144(1):76-79. DOI: 10.1016/j.ejogrb.2009.02.004.

14. Ozgur H, Elena $\mathrm{T}$, Sertac $\mathrm{E}$, et al. A comparison of short-term outcomes between laparoscopic supracervical and total hysterectomy. Am J Obstet Gynecol 2009;201(5):536.e1-536.e7. DOI: 10.1016/j.ajog.2009.07.048.

15. Kafy S, Al-Sannan B, Kabli N, et al. Patient satisfaction after laparoscopic total or supracervical hysterectomy. Gynecol Obstet Invest 2009;67(3):169-172. DOI: 10.1159/000184679.

16. Einarsson Jl, Suzuki Y, Vellinga TT, et al. Prospective evaluation of quality of life in total versus supracervical laparoscopic hysterectomy. J Minim Invasive Gynecol 2011;18(5):617-621. DOI: 10.1016/j. jmig.2011.06.003.

17. Berlit S, Tuschy B, Wuhrer A, et al. Sexual functioning after total versus subtotal laparoscopic hysterectomy. Arch Gynecol Obstet 2018;298(2):337-344. DOI: 10.1007/s00404-018-4812-7.

18. Ghomi A, Hantes J, Lotze EC. Incidence of cyclical bleeding after laparoscopic supracervical hysterectomy. J Minim Invasive Gynecol 2005;12(3):201-205. DOI: 10.1016/j.jmig.2005.03.008.

19. Hellstrom AC, Sigurjonson T, Pettersson F. Carcinoma of the cervical stump. The radiumhemmet series 1959-1987. Treatment and prognosis. Acta Obstet Gynecol Scand 2001;80(2):152-157. 